\title{
Comparisons of the Safety of Hydromorphone Hydrochloride Solution for Patient Controlled Analgesia When Prepared Under Hospital Ward and Pharmacy Intravenous Admixture Services Environments
}

\author{
JUAN HOU, PING LIANG, YUYAN ZHOU ${ }^{1}$, TENG GUO, HUAN YANG ${ }^{2}$, ZILIN WANG ${ }^{3}$ AND JIANG LIU* \\ Department of Pharmacy, The Fourth Hospital of Hebei Medical University, ${ }^{1}$ Hebei Institute for Drug and Medical Device \\ Control, ${ }^{2}$ Library Statistics Center, The Fourth Hospital of Hebei Medical University, Shijiazhuang, Hebei 050011, ${ }^{3} \mathrm{Hebei}$ \\ Medical University, Shijiazhuang, Hebei 050017, China
}

Hou et al: Safety of Hydromorphone Hydrochloride Solution for Patient Controlled Analgesia

\begin{abstract}
To determine the safety of hydromorphone hydrochloride solution for long term use in patient controlled analgesia by comparing the microbial contamination of preparations made under hospital ward dispensing room and pharmacy intravenous admixture service operating environment. Hydromorphone hydrochloride solutions were prepared in the patient controlled analgesia pump using $0.9 \%$ sodium chloride under ward dispensing room or pharmacy intravenous admixture service operating environments. The solutions were stored at $25^{\circ}$ and $37^{\circ}$ and inspected for clarity and tested for bacterial endotoxin contamination for $15 \mathrm{~d}$. The hydromorphone hydrochloride solution prepared under the ward dispensing room remained clear and endotoxin levels were below detection limits for $9 \mathrm{~d}$. On $\mathrm{d}$ 11, this solution appeared turbid with slightly increased bacterial endotoxin levels. No remarkable observations were noted in the solution prepared under the pharmacy intravenous admixture service environment for the duration of the experiment. Hydromorphone hydrochloride solution prepared under the ward dispensing room conditions remained safe for use for only $9 \mathrm{~d}$ after preparation. On the other hand, the solution prepared under pharmacy intravenous admixture service remained suitable for use for longer as no contamination was observed for the duration of the study.
\end{abstract}

Key words: Hydromorphone hydrochloride, patient controlled analgesia pump, pharmacy intravenous admixture service, microbial contamination

Patient Controlled Analgesia (PCA) is a pain management technique in which the dose of analgesic drugs is pre-set by a medical staff and the delivery of the drugs controlled by the patient as need arises. Therefore, PCA can be administered on demand leading to adequate analgesic effects and is often applied in postoperative pain management.

In recent years, PCA has been employed in managing pain among patients with advanced cancer in China. The technique has proved useful, providing satisfactory analgesic effects and improving the quality of life of these patients who are usually at the end-stage of cancer.

It is critical to assure the long-term safety of the drugs used for PCA. Both drug stability and the risk of bacterial infections have a great bearing on the expiration of the drug after dispensing. Several studies report on the stability of hydromorphone or hydromorphone mixed with other drugs in glass bottles, infusion bags and injection tools ${ }^{[1-8]}$. Khondkar et al. showed that hydromorphone hydrochloride solution remained clear and sterile after storing at different temperatures for $16 \mathrm{w}^{[7]}$. On the other hand, Mary et al. found that hydromorphone hydrochloride solution, when mixed with ketamine, remained sterile for $7 \mathrm{~d}$ at room temperature after preparation ${ }^{[8]}$. Notably, these studies did not indicate the operation environment for dispensing the concerned drugs and there are no

This is an open access article distributed under the terms of the Creative Commons Attribution-NonCommercial-ShareAlike 3.0 License, which allows others to remix, tweak, and build upon the work non-commercially, as long as the author is credited and the new creations are licensed under the identical terms

Accepted 21 September 2021 Revised 22 February 2021 Received 20 February 2020

*Address for correspondence E-mail: liujiang_9558@126.com 
reports on the safety of the drug preparations in PCA pumps. In China, the dispensing of drugs used in analgesia is generally performed by nurses in the ward dispensing room. This environment is not sterile and the dispensing process is not aseptic. Moreover, how long the hydromorphone hydrochloride PCA pump can be used before the preparation is rendered unsafe due to instability or microbial contamination remains unknown. In this study, we analyzed the microbial contamination of hydromorphone hydrochloride injection intended for PCA use prepared under the dispensing room in comparison to that prepared under the pharmacy intravenous admixture services.

\section{MATERIALS AND METHODS}

\section{Instruments and reagents:}

SPX-150B biochemical incubator (Shanghai Yuejin Medical Device Factory), electric thermostatic incubator (Shanghai Yuejin Medical Device Factory), HTY-2000 type bacteria collector (Hangzhou Tailin Biotechnology Equipment Co., Ltd.), fully enclosed bacteria collection Incubator (Hangzhou Tailin Biotechnology Equipment Co., Ltd.), VITEK 2 automatic bacterial identification and drug sensitivity system (BioMérieux) were used.

Hydromorphone hydrochloride injection ( $2 \mathrm{ml}: 2 \mathrm{mg}$, lot number: 1150601) was purchased from Yichang Renfu Pharmaceutical Co., Ltd. while $0.9 \%$ sodium chloride injection $(500 \mathrm{ml}: 4.5 \mathrm{~g}$, lot number: 5L84G4 ) was donated by China Otsuka Pharmaceutical Co., Ltd. Tryptic soy mash liquid medium (Beijing Luqiao Technology Co., Ltd., lot number: 151214), thioglycolate fluid medium (Merck, Germany, lot number: VM720391 602), Tryptic Soy Agar (TSA) medium (Beijing Luqiao Technology Co., Ltd, lot number: 151202), $0.1 \%$ peptone water (Guangdong Huankai Microbial Technology Co. Lot number: 3106240) and sarcaster glucose agar medium (Beijing Sanyao Technology Development Corporation. Lot number: 1711212) were also used.

\section{Bacteria:}

Staphylococcus aureus [CMCC (B) 26 003], Pseudomonas aeruginosa [CMCC (B) 10 104], Bacillus subtilis [CMCC (B) 63 501], Clostridium sporogenes [CMCC (B) 64 941], Candida albicans [CMCC (F) 98 001] and Aspergillus niger [CMCC (F) 98 003] were obtained from the China Medical Bacteria Collection Management Center.

\section{Solution preparation:}

The solution was prepared under two different environments. In the first case, hydromorphone hydrochloride solution was prepared in the dispensing ward room whereas in the second instance, the drug was prepared at the Pharmacy Intravenous Drug Preparation Center (PIVAS). The hydromorphone hydrochloride was dissolved in $0.9 \%$ sodium chloride in a PCA pump storage bag $(40 \mathrm{ml})$. The resultant solutions, prepared in either of the two environments, were stored both at room temperature $\left(25^{\circ}\right)$ for the one prepared in the dispensing room and at physiological body temperature $\left(37^{\circ}\right)$.

\section{Examination for clarity and bacterial endotoxin contamination:}

The clarity of the solutions was evaluated by lamp inspection under 2000LX light on d 0, 1, 2, 3, 5, 7, 9, 11,13 and 15 after preparation.

Preparation of a standard curve of 10-0.01 EU/ml endotoxin was proposed based on the recommended endotoxin limit (L) of $88.0 \mathrm{EU} / \mathrm{mg}$ of hydromorphone hydrochloride injection. According to the equation: Maximum ValidDilution $(M V D)=c L / \lambda$ (c: concentration of sample solution, $\lambda$ : lysate sensitivity), the MVD of hydromorphone was determined to be 422 times; that is, for accurate and reliable endotoxin measurement, the maximum allowable dilution of hydromorphone in the experiment must not exceed 422 times.

According to the method specified in the Chinese Pharmacopoeia (2015), the bacterial endotoxin standard $(80 \mathrm{EU} / \mathrm{ml})$ was dissolved with Bacterial Endotoxin Test water (BET water) and then serially diluted to 10, 1, 0.1 and $0.01 \mathrm{EU} / \mathrm{ml}$. These concentrations were used to construct the standard curve in the bacterial endotoxin analyzer. The standard curve equation was determined by the computer automatically as follows:

$\log \mathrm{T}=2.7687-0.2806 \log \mathrm{C}$

Where, $\log \mathrm{T}$ : $\log$ arithm of average response time, $\log \mathrm{C}$ : logarithm of endotoxin concentration, $r=-0.9999$. The results showed that the standard curve was established when the bacterial endotoxin concentration was in the range 10-0.01 EU/ml.

The prepared hydromorphone hydrochloride solution was diluted with BET water to make 4-, 8- and 16 -fold diluted solutions. The sample containing 0.5 $\mathrm{EU} / \mathrm{ml}$ endotoxin was used as the positive control and it was treated to the same dilution protocol as 
the hydromorphone hydrochloride solution. For the negative control, BET water was used. Each sample was divided into two separate parallel tubes and tested according to the bacterial endotoxin test method. The results showed that the 8-fold dilution of hydromorphone hydrochloride had the smallest interference effect (Table 1). Therefore, this dilution was selected for the experiment.

Thereafter, bacterial endotoxin levels of hydromorphone hydrochloride solutions at high, medium and low concentrations $(1 \mathrm{mg} / \mathrm{ml}, 0.1 \mathrm{mg} / \mathrm{ml}$ and $0.048 \mathrm{mg} / \mathrm{ml}$, respectively) were detected under the established optimal dilution to verify the feasibility of the detection method. Results showed that the coefficient of variation between parallel tubes of the three batches of solutions was less than $10 \%$ and that the recovery of the positive control was in the range of $50-200 \%$ (Table 2). Thus, the 8 -fold dilution was selected for the experiment. Using the experimental conditions determined above, bacterial endotoxin levels were measured on $\mathrm{d} 0,1,2,3,5,7,9,11,13$ and 15 after the preparation of the two sample solutions.

\section{Sterility analysis:}

Pseudomonas aeruginosa, Staphylococcus aureus and Bacillus subtilis were inoculated in pancreatic soybean mash liquid medium according to the Chinese Pharmacopoeia (2015 edition) and cultured at $33^{\circ}$ for $24 \mathrm{~h}$. Clostridium sporogenes was inoculated in thioglycolate fluid culture medium and incubated at $33^{\circ}$ for $24 \mathrm{~h}$. Candida albicans was inoculated in S. dextrose agar medium and cultured at $23^{\circ}$ for $48 \mathrm{~h}$. These cultures were made up to $50-100 \mathrm{cfu} / \mathrm{ml}$ using $0.9 \%$ sodium chloride solution. Aspergillus niger was inoculated onto glucose agar slant culture medium and maintained at $23^{\circ}$ for $7 \mathrm{~d}$. Thereafter, the spores were eluted using $10 \mathrm{ml}$ of $0.9 \%$ sodium chloride solution. Next, the spore suspension was aspirated into a sterile test tube and prepared into a microbial solution of $50-100 \mathrm{cfu} / \mathrm{ml}^{-1}$ using $0.9 \%$ aseptic sodium chloride solution.

For the test group, $20 \mathrm{ml}$ of hydromorphone hydrochloride solution was obtained under aseptic conditions from the PCA pump storage bag, filtered using membrane filtration and then rinsed six times using $100 \mathrm{ml}$ of $0.1 \%$ peptone water. Thereafter, bacterial suspensions $(1 \mathrm{ml})$, as described previously, were added in turns during the final $100 \mathrm{ml}$ rinse using peptone water. Following this step, thioglycolate fluid medium and tryptic soy bean paste liquid culture medium were added and the set-up incubated for $5 \mathrm{~d}$ (the thioethanolate fluid medium was maintained at $33^{\circ}$ while the tryptic soy bean paste liquid culture medium was kept at $23^{\circ}$ ). Unfiltered hydromorphone hydrochloride solution was used as control solution (control group). All other operations and procedures were the same as for the test group. These were used to analyze the applicability of this method. The prepared test solution had no bacteriostatic effect or negligible effect on the six test bacteria under the test

TABLE 1: PRELIMINARY EXPERIMENT OF HYDROMORPHONE HYDROCHLORIDE INTERFERENCE

\begin{tabular}{|c|c|c|c|c|c|c|}
\hline Samples & $\begin{array}{c}\text { Dilution } \\
\text { fold }\end{array}$ & $\begin{array}{c}\text { Response } \\
\text { time (s) }\end{array}$ & CV & $\mathrm{RC}$ & $\begin{array}{l}\text { Calculated endotoxin } \\
\text { concentration (EU/ml) }\end{array}$ & $\begin{array}{c}\text { Endotoxin } \\
\text { concentration }(\mathrm{EU} / \mathrm{ml})\end{array}$ \\
\hline NC & & $>4320$ & & & & $<$ LOD \\
\hline NC & & $>4320$ & & & & $<L O D$ \\
\hline PC & & 649 & $0.55 \%$ & & 0.7095 & 0.7095 \\
\hline PC & & 644 & & & & \\
\hline \multirow{12}{*}{$\begin{array}{l}\text { Hydromorphone } \\
\text { hydrochloride }\end{array}$} & 4 & 914 & $2.20 \%$ & & 0.2182 & 0.8728 \\
\hline & 4 & 886 & & & & \\
\hline & 4 & 622 & $0.34 \%$ & $120 \%$ & 0.8212 & \\
\hline & 4 & 619 & & & & \\
\hline & 8 & 1172 & $3.02 \%$ & & 0.0918 & 0.7344 \\
\hline & 8 & 1123 & & & & \\
\hline & 8 & 633 & $1.01 \%$ & $138 \%$ & 0.7846 & \\
\hline & 8 & 624 & & & & \\
\hline & 16 & 1405 & $1.78 \%$ & & 0.0467 & 0.7472 \\
\hline & 16 & 1370 & & & & \\
\hline & 16 & 622 & $0.57 \%$ & $151 \%$ & 0.8026 & \\
\hline & 16 & 627 & & & & \\
\hline
\end{tabular}


conditions. The sterility inspection of the test product can be performed with Staphylococcus aureus as a positive control according to the inspection method and inspection conditions (Table 3).

From each sample, $20 \mathrm{ml}$ was obtained and stored at $25^{\circ}$ and $37^{\circ}$ on $\mathrm{d} 0,1,2,3,5,7,9,11,13$ and 15 (Experimental group). The sample aliquots were diluted using $0.9 \%$ sodium chloride solution, passed through membrane filtration and rinsed six times using $100 \mathrm{ml}$ of $0.1 \%$ peptone water. Subsequently, thioglycolate fluid medium and tryptic soy bean paste liquid culture medium were added and the preparation cultured for $14 \mathrm{~d}$ (the thioethanolate fluid medium was kept at $33^{\circ}$ while the tryptic soy bean paste liquid culture medium at $23^{\circ}$ ). $1 \mathrm{ml}$ of the above Staphylococcus aureus bacterial solution was added to the rinsed peptone water at the final rinsing step as a positive control while the test solution that was not filtered was used as the control solution (control group). Other procedures were similar to those carried out in the experimental group.

\section{RESULTS AND DISCUSSION}

The hydromorphone hydrochloride solution prepared in the ward was clear from $\mathrm{d} 0$ to 9 at both $25^{\circ}$ and $37^{\circ}$ with no visible foreign bodies or turbidity. However, cloudy bands were faintly visible on the $11^{\text {th }} \mathrm{d}$ and the solution was significantly cloudy on the $15^{\text {th }} \mathrm{d}$. On the other hand, the hydromorphone hydrochloride solution prepared under PIVAS conditions were clear all through to the $15^{\text {th }} \mathrm{d}$ at the two storage temperatures with no foreign matter or turbidity present (Table 4). At both testing temperatures of $25^{\circ}$ and $37^{\circ}$, the bacterial endotoxin levels in the hydromorphone hydrochloride solution prepared in the ward environment remained constant for the first $11 \mathrm{~d}$. A slight increase was noted from $\mathrm{d} 13$ to 15 although the concentration was less than $0.03 \mathrm{EU} / \mathrm{ml}$. As for the preparation conducted under PIVAS conditions, the bacterial endotoxin levels in the solution remained less than $0.01 \mathrm{EU} / \mathrm{ml}$ throughout the study period.

At both testing temperatures, the hydromorphone hydrochloride solution prepared under the ward condition was clear for the first $9 \mathrm{~d}$ of the experiment. Turbidity, however, was observed on d 11 (Table 5). When an aliquot of the turbid medium solution was transferred to another thioglycolate fluid medium and cultured at the prescribed temperature for $2 \mathrm{~d}$, the turbidity phenomenon still appeared. The culture was

\section{TABLE 2: INTERFERENCE EXPERIMENT OF HYDROMORPHONE HYDROCHLORIDE}

\begin{tabular}{|c|c|c|c|c|c|c|}
\hline Samples & $\begin{array}{l}\text { Dilution } \\
\text { fold }\end{array}$ & $\begin{array}{c}\text { Response } \\
\text { time (s) }\end{array}$ & $\mathrm{CV}$ & $\mathrm{RC}$ & $\begin{array}{l}\text { Calculated endotoxin } \\
\text { concentration }(\mathrm{EU} / \mathrm{ml})\end{array}$ & $\begin{array}{c}\text { Endotoxin } \\
\text { concentration (EU/ml) }\end{array}$ \\
\hline $\mathrm{NC}$ & & $>4080$ & & & & $<L O D$ \\
\hline NC & & $>4080$ & & & & $<L O D$ \\
\hline PC & & 638 & $5.02 \%$ & & 0.6538 & 0.6538 \\
\hline PC & & 685 & & & & \\
\hline \multirow{5}{*}{$\begin{array}{l}\text { Hydromorphone } \\
\text { hydrochloride (high } \\
\text { concentration) }\end{array}$} & 8 & 1350 & $0.68 \%$ & & 0.0506 & 0.2024 \\
\hline & 8 & 1363 & & & & \\
\hline & 8 & 685 & $3.42 \%$ & $95 \%$ & 0.529 & \\
\hline & 8 & 719 & & & & \\
\hline & 8 & 682 & $0.00 \%$ & & 0.0586 & 0.1946 \\
\hline \multirow{4}{*}{$\begin{array}{l}\text { Hydromorphone } \\
\text { hydrochloride (medium } \\
\text { concentration) }\end{array}$} & 8 & 682 & & & & \\
\hline & 8 & 549 & $1.78 \%$ & $110 \%$ & 0.6087 & \\
\hline & 8 & 563 & & & & \\
\hline & 8 & 1397 & $1.05 \%$ & & 0.0456 & 0.1824 \\
\hline \multirow{3}{*}{$\begin{array}{l}\text { Hydromorphone } \\
\text { hydrochloride (low } \\
\text { concentration) }\end{array}$} & 8 & 1396 & & & & \\
\hline & 8 & 659 & $1.38 \%$ & $118 \%$ & 0.6399 & \\
\hline & 8 & 672 & & & & \\
\hline
\end{tabular}

Note: $C V=$ variable coefficient; $R C=$ recovery; $L O D=$ limit of detection $N C=$ negative control $P C=$ positive control

TABLE 3: APPLICABILITY OF STERILITY TEST METHOD

\begin{tabular}{|c|c|c|c|c|c|c|}
\hline & $\begin{array}{c}\text { Staphylococcus } \\
\text { aureus }\end{array}$ & $\begin{array}{c}\text { Pseudomonas } \\
\text { aeruginosa }\end{array}$ & $\begin{array}{l}\text { Bacillus } \\
\text { subtilis }\end{array}$ & $\begin{array}{l}\text { Clostridium } \\
\text { sporogenes }\end{array}$ & $\begin{array}{l}\text { Candida } \\
\text { albicans }\end{array}$ & $\begin{array}{c}\text { Aspergillus } \\
\text { niger }\end{array}$ \\
\hline Test group & + & + & + & + & + & + \\
\hline Control group & + & + & + & + & + & + \\
\hline
\end{tabular}

Note: "+" represented the bacterial growth 
TABLE 4: CLARITY OF HYDROMORPHONE HYDROCHLORIDE SOLUTION

\begin{tabular}{|c|c|c|c|c|c|c|c|c|c|c|c|}
\hline & Storage temperature & $0 \mathrm{~d}$ & $1 \mathrm{~d}$ & $2 \mathrm{~d}$ & $3 d$ & $5 d$ & $7 d$ & $9 \mathrm{~d}$ & $11 \mathrm{~d}$ & $13 d$ & $15 d$ \\
\hline \multirow{2}{*}{ Ward dosing group } & $25^{\circ}$ & - & - & - & - & - & - & - & + & ++ & +++ \\
\hline & $37^{\circ}$ & - & - & - & - & - & - & - & + & ++ & +++ \\
\hline \multirow{2}{*}{ PIVAS dosing group } & $25^{\circ}$ & - & - & - & - & - & - & - & - & - & - \\
\hline & $37^{\circ}$ & - & - & - & - & - & - & - & - & - & - \\
\hline
\end{tabular}

Note: "+" represented that the solution was turbid; "Number of + " represented the degree of turbidity for the solution; "-" represented that the solution was clear

TABLE 5: BACTERIA GROWN IN THE HYDROMORPHONE HYDROCHLORIDE SOLUTION

\begin{tabular}{|c|c|c|c|c|c|c|c|c|c|c|c|}
\hline & Storage temperature & $0 \mathrm{~d}$ & $1 \mathrm{~d}$ & $2 d$ & $3 d$ & $5 d$ & $7 d$ & $9 \mathrm{~d}$ & $11 \mathrm{~d}$ & $13 \mathrm{~d}$ & $15 \mathrm{~d}$ \\
\hline Ward dosino oroun & $25^{\circ}$ & - & - & - & - & - & - & - & + & + & + \\
\hline wara dosing group & $37^{\circ}$ & - & - & - & - & - & - & - & + & + & + \\
\hline PIVAS dosing aroun & $25^{\circ}$ & - & - & - & - & - & - & - & - & - & - \\
\hline PIVAS UOSIIIS SIUUT & $37^{\circ}$ & - & - & - & - & - & - & - & - & - & - \\
\hline PC & & + & + & + & + & + & + & + & + & + & + \\
\hline NC & & - & - & - & - & - & - & - & - & - & - \\
\hline
\end{tabular}

Note: "+" represented the bacterial growth; "-" represented no bacterial growth

then aseptically streaked on the surface of TSA medium and inoculated at $33^{\circ}$ for $2 \mathrm{~d}$. Subsequently, a single colony was isolated and confirmed to be Staphylococcus epidermidis using the VITEK 2 system. In contrast, samples prepared under PIVAS environment showed no turbidity and no bacterial growth was evident for the $15 \mathrm{~d}$ of the experiment.

The administration of hydromorphone hydrochloride using PCA has proven vital in controlling pain and enhancing the quality of life among end-stage cancer patients. The technique is particularly important for long duration of analgesic use. It is therefore important to assure physical and chemical stability as well as freedom from bacterial contamination of such a preparation to prevent occurrence of undesirable adverse events ${ }^{[-14]}$. In this study, we evaluated the sterility of the hydromorphone hydrochloride solutions prepared under ward and PIVAS conditions.

In China, the use of PCA among patients with advanced cancer generally does not exceed $15 \mathrm{~d}$ therefore informing the duration of the current study. The results obtained showed that the hydromorphone hydrochloride solution in the PCA pump prepared in the general ward environment was relatively safe within $9 \mathrm{~d}$ of preparation but the safety of the solution cannot be guaranteed after $10 \mathrm{~d}$ as there was a higher risk of bacterial contamination. On the contrary, the hydromorphone hydrochloride solution prepared in the PIVAS environment was determined to be relatively safe throughout the $15 \mathrm{~d}$ of the experiment. However, whether the preparation remains sterile and safe for use beyond $15 \mathrm{~d}$ requires further investigation.

Bacterial endotoxin produced after lysis of the cell wall of gram-negative bacteria is pyrogenic. Use of an injectable solution contaminated by endotoxin risks may cause fever, multi-organ failure and shock among other manifestations of endotoxemia with potential fatality. According to the Chinese pharmacopoeia and many other international formularies, bacterial endotoxin detection is a mandatory test for medicinal substances intended for injection. In our study, the solution prepared in the ward showed bacterial growth on $\mathrm{d} 11$ but the bacterial endotoxin concentration did not exceed the recommended pharmacopeial limit of $0.05 \mathrm{EU} / \mathrm{ml}$. The inconsistent results may be due to the unevenness during sampling, which leads to experimental errors or to the cultured bacteria were gram-positive Staphylococcus, which has a different cell wall structure from gram-negative bacteria. Results obtained for sterility and bacterial endotoxin testing are dependent on the type of contaminating bacteria $^{[15,16]}$. According to CHINET, China Bacteria Resistance Monitoring Network 2016, gram-negative bacteria account for $71.6 \%$ of clinical isolates. By extrapolation, therefore, nosocomial infections are often likely to be caused by gram-negative bacteria. This necessitates inspection of injectable solutions for bacterial endotoxins to prevent bacteremia due to such contamination.

In current study, the bacterium isolated on the $11^{\text {th }} \mathrm{d}$ in the sample prepared under ward conditions was Staphylococcus epidermidis, an important source of cross infection in hospitals. Having its origin in the human epidermis, the bacterium may have likely been introduced by the person preparing the hydromorphone hydrochloride injection. However, it is not only Staphylococcus epidermidis that can cause crossinfection in hospitals; seasonal changes also influence the abundance of microorganisms and hence the risk of 
implications in causing infections. Profiling for other pathogens would require further parallel experiments during different weather and seasonal patterns. Maintaining sterility in the preparation environment together with ensuring aseptic operation techniques is critical in avoiding microbial contamination. The PIVAS procedure is largely compliant with Good Manufacturing Practice (GMP) standards. Liquid dispensing is performed in a local 100-level clean laminar flow table or biological safety cabinet and strict aseptic operation techniques are implemented. Adherence to the GMP protocols can block microbial contamination from the source, ensuring the sterility of the drug and thus preventing introduction of microorganisms into the patient as a result of the process.

However, due to various constraints, not all infusions in China are prepared by PIVAS. It is therefore recommended that the ward where injectable solutions are to be prepared be equipped with a sterile operation room or operation table to implement the concept of aseptic operation. This has the potential to limit human and environmental factors that may contaminate the infusion. Such a step will improve the safety of the preparation and hence of the patient, post-infusion.

Our study also shows that unlike the PIVAS-prepared injections which remained bacteria-free for the duration of the study, the solution prepared under the ward conditions can only be stored for a relatively shorter period of time ( $9 \mathrm{~d}$ ) before it is rendered unsuitable due to possibilities of bacterial contamination. Furthermore, the study indicates that the stability and integrity of the solutions prepared by either method did not vary according to the testing temperatures. This suggests that patients can carry along the PCA pumps as body temperature does not appear to increase the risk of causing bacterial contamination.

\section{Conflict of interests:}

The authors declare that they have no conflict of interest.

\section{REFERENCES}

1. Walker S, Law S, Deangelis C. Stability and Compatibility of Hydromorphone and Ketamine in Normal Saline. Can J Hosp Pharm 2001;54.
2. Trissel LA, Xu QA, Pham L. Physical and chemical stability of hydromorphone hydrochloride 1.5 and $80 \mathrm{mg} / \mathrm{ml}$ packaged in plastic syringes. Int J Pharm Compd 2002;6(1):74-6.

3. Shields D, Montenegro R, Ragusa M. Chemical stability of admixtures combining ziconotide with morphine or hydromorphone during simul ated intrathecal administration. Neuromodulation 2005;8(4):257-63.

4. Rudich Z, Peng P, Dunn E, McCartney C. Stability of clonidine in clonidine-hydromorphone mixture from implanted intrathecal infusion pumps in chronic pain patients. J Pain Symptom Manage 2004;28(6):599-602.

5. Hildebrand KR, Elsberry DE, Anderson VC. Stability and compatibility of hydromorphone hydrochloride in an implantable infusion system. J Pain Symptom Manage 2001;22(6):1042-7.

6. Anderson C, MacKay M. Stability of fentanyl citrate, hydromorphone hydrochloride, ketamine hydrochloride, midazolam, morphine sulfate, and pentobarbital sodium in polypropylene syringes. Pharmacy 2015;3(4):379-85.

7. Chopra P, CPhT JA. Chemical stability of hydromorphone hydrochloride in patient-controlled analgesia injector. Int $\mathrm{J}$ Pharm Compd 2010;14(2):160-4.

8. Ensom MH, Decarie D, Leung K, Montgomery C. Stability of hydromorphone-ketamine solutions in glass bottles, plastic syringes and IV bags for pediatric use. Can J Hosp Pharm 2009;62(2):112-8.

9. Liang P, Hou J, Shi X, Li B, Wang M, Zhou X, et al. Stability Study of Hydromorphone Hydrochloride Under Different Conditions. Chin J Mod Appl Pharm 2017;34(10077693):1150-3.

10. Peterson JS, Rockwell K Jr., Scott IU, Ip MS, VanVeldhuisen PC, Blodi BA. Long-term physical stability, sterility, and antivegf bioactivity of repackaged Bevacizumab in $2 \mathrm{ml}$ glass vials. Retina 2019;39(9):1802-9.

11. Parish HG, Morton JR, Brown JC. A systematic review of epinephrine stability and sterility with storage in a syringe. Allergy Asthma Clin Immunol 2019;15(1):1-3.

12. de Lima Farah J, Sano R, Maugéri IM, Teixeira D, Ishimura ME, Martins G, et al. Evaluation of aflibercept and zivaflibercept binding affinity to vascular endothelial growth factor, stability and sterility after compounding. Int J Retina Vitreous 2018;4(1):1-7.

13. Moffett BS, Dinh K, Placencia J, Pelkey G, Hui SK, Teruya J. Stability and Sterility of Enoxaparin $8 \mathrm{mg} / \mathrm{mL}$ Subcutaneous Injectable Solution. J Pediatr Pharmacol Ther 2016;21(4):3226.

14. Micard S, Rieutord A, Prognon P, Hassan M, Brion F. Stability and sterility of meglumine gadoterate injection repackaged in plastic syringes. Int J Pharm 2001;212(1):93-9.

15. Mao S, Chen L. Discussion on bacterial endotoxin (pyrogen) and sterility in infusion examination. Strait Pharm J 1998;33:1006-3765.

16. LR. The bacterial toxicity and sterility of the retained liquid after the use of solvent for bottled injection were investigated. Inner Mongolia Tradit Chin Med 2014;33(1521-690x):72-3. 